\title{
STABILITAS STRUKTUR TANAH JENIS EKSPANSIF MENGGUNAKAN KOMBINASI ABU DAUN
}

\author{
Rekso Ajiono ${ }^{1}$, Herlan Pratikto ${ }^{2}$ \\ ${ }^{1,2}$ Fakultas Teknik Universitas Kadiri
}

Email : ${ }^{1}$ rekso_ajiono@unik-kediri.ac.id, ${ }^{2}$ herlan_pratikto@unik-kediri.ac.id

\begin{abstract}
In the field of land construction is a core foothold media of a building. Soil structure which contains mostly clay in its components is Monmorillonite. The level of soil stability that is Montmorillonite is somewhat less good for the support of building infrastructure. The method of soil stability in the following research is to use leaf ash in addition variations of $5 \%, 10 \%, 15 \%$ and $20 \%$ by conducting a Water Content test and gradation test on the original soil structure used as a research sample. Soil test samples are taken from residential areas beautiful town of Kediri which is Montmorillonite. The soil stability test is to use montmorillonite soil mix specimens with leaf ash by carrying out tests of Content Weight, Atterberg Limit and Proctor. The results of the original soil structure research were categorized momoroillonite and after adding coffee grounds in addition to the maximum variation of $20 \%$, the Liquid Limit value rose to $43 \%$ and the Plastic Limit value increased to $31.64 \%$, so that the plastic index could increase to $11.36 \%$ When compaction test with perfect solid specimens, the original dry soil volume weight was $6.72 \mathrm{gr} / \mathrm{cm} 3$ and after adding ash ash by $20 \%$ increased the dry volume weight to $10.56 \mathrm{gr} / \mathrm{cm} 3$.
\end{abstract}

Keywords: Soil, Leaf ash, Soil Stability

ABSTRAK

Dalam bidang konstruksi Tanah adalah suatu media pijakan inti dari sebuah bangunan. Struktur Tanah yang sebagian banyak terdapat lempung didalam komponennya adalah bersifat Monmorillonite. Tingkat stabilitas tanah yang bersifat Montmorillonite terbilang kurang bagus terhadap daya topang infrastruktur bangunan. Cara stabilitas tanah pada penelitian berikut adalah dengan menggunakan abu daun pada variasi penambahan $5 \%$, $10 \%, 15 \%$ dan 20\% dengan melakukan pengujian Water Content dan uji gradasi pada struktur tanah asli yang digunakan sebagai sampel penelitian, Uji tanah sampel diambil dari area perumahan wilis indah kota Kediri yang bersifat Montmorillonite. Pada test uji stabilitas tanah adalah dengan menggunakan benda uji mix tanah montmorillonite dengan abu daun dengan melakukan uji Berat Isi, Batas konsistensi (Atterberg Limit) dan Pemadatan Tanah (Proctor). Pada hasil penelitian struktur tanah asli dikategorikan momoroillonite dan setelah ditambah ampas kopi pada penambahan divariasi maksimal sebesar 20\%, nilai Liquid Limit naik menjadi $43 \%$ dan nilai Plastic Limit mengalami kenaikan menjadi 31,64\%, sehingga index plastic dapat mengalami peningkatan menjadi $11,36 \%$. Saat uji pemadatan dengan kondisi benda uji padat sempurna, berat volume kering tanah asli sebesar $6,72 \mathrm{gr} / \mathrm{cm}^{3}$ dan setelah ditambahkan abu daun sebesar $20 \%$ mengalami peningkatan berat volume kering menjadi $10,56 \mathrm{gr} / \mathrm{cm}^{3}$.

Kata Kunci: Tanah, Abu daun, Stabilitas Tanah

\section{PENDAHULUAN}

\subsection{TINJAUAN UMUM}

Tanah merupakan suatu bahan maupun media dari suatu pembangunan seluruh konstruksi penunjang kegiatan mahluk hidup. "fungsi dari tanah itu sendiri adalah sebagai media pijakan inti dari sebuah bangunan" [1], sehingga pada keselarasan penyokong pondasi seluruh bangunan "memikul beban dari kolom yang kemudian menyalurkannya ke lapisan tanah keras" [2]. Dengan adanya demikian didalam 
setiap perencanaan pembangunan konstruksi diharapkan dalam perletakannya harus terdapat struktur tanah yang mampu untuk menopang beban bangunan diatasnya. Didalam setiap lokasi rencana pembangunan, tidak selalu terdapat struktur tanah keras. Hal demikian disebabkan karena jenis tanah berbeda - beda menganut faktor geologi setiap lokasi masing - masing. Jenis - jenis tanah terbagi menjadi beberapa kriteria, seperti batuan, pasir, lempung dan debu. "Lempung ekspansif memiliki potensi kembang susut tinggi apabila terjadi perubahan kadar air", [3]. "Tanah ekspansif adalah tanah bermasalah yang memiliki kekuatan yang rendah dan potensi kembang susut tinggi karena perubahan kadar air tanah", [4]. Sifat lempung menurut E. Bowless adalah, "Lempung bersifat plastis pada kadar air sedang, dalam keadaan kering lempung sangat keras dan tidak mudah dikelupas hanya dengan jari" [1], [5], dengan demikian harus dilakukan upaya - upaya untuk stabilitas tanah, "Stabilisasi tanah dapat dilakukan dengan cara mekanik yaitu dengan pemadatan menggunakan energi mekanik untuk menghasilkan pemampatan partikel, atau secara kimiawi yaitu dengan mencampur tanah asli dengan bahan tambah tertentu", [3]. Dalam penyusunan paper berikut ini adalah berkonsep tentang upaya stabilitas tanah menggunakan kombinasi abu daun dan semen portland dengan variasi kombinasi sebesar 5\%,10\%, 15\% dan 20\%. Abu daun yang akan dipergunakan merupakan sebuah sisa - sisa pembakaran dari daun kering yang sudah tidak terpakai, Daun dalam skala besar merupakan "limbah padat organik yang sukar dalam penguraiannya secara biologis", [1]. sehingga sangat efisien jika digunakan sebagai media stabilitas tanah ekspansif dalam penelitian paper berikut dengan judul berjudul STABILITAS STRUKTUR TANAH JENIS EKSPANSIF MENGGUNAKAN KOMBINASI ABU DAUN. Dalam perekatan bahan - bahan tersebut digunakan jenis semen portland. Fungsi semen portland secara spesifik, "bahan perekat atau lem, yang bisa merekatkan bahan - bahan material lain". Pada metodologi pelaksanaan prosedur pengujian dengan melakukan pengujian batas konsistensi tanah (index plastic) dan pemadatan tanah (proctor).

\section{METODE PENELITIAN}

\subsection{MATERIAL}

\section{A. Tanah Lempung}

Faktor kandungan jumlah air tanah berlempung sangat berimbas pada sifat mekanik tanah ekspansif, dilain sisi "Kondisi secara umum kadar air pada tanah berubah - ubah dari keadaan 
jenuh", [6]. Hal tersebut sebagai penyebab kurangnya konsisten sifat mekanik struktur tanah. karena pada dasarnya, "Lempung bersifat plastis pada kadar air sedang", [3].Struktur tanah yang akan digunakan dalam media percobaan adalah struktur tanah lempung yang nilai stabilitasnya rendah dan bersifat Ekspansif yang dimaksudkan untuk hasil signifikan dalam upaya stabilitas tanah.

B. Air

Air yang akan dipergunakan sebagai media pelarut sampel uji stabilitas tanah didapat dari saluran air bersih laboratorium teknik sipil Universitas Kadiri, yang pada dasarnya "Zat kimia ini merupakan sebuah zat pelarut yang penting, memiliki kemampuan untuk melarutkan zat kimia lainya", [1] [5].

C. Abu Daun

Media komposisi pendukung sebagai stabilitas tanah di penelitian berikut merupakan abu daun kering yang diambil dari beberapa titik diwilayah kediri sejumlah kebutuhan penelitian. Abu daun sendiri merupakan suatu partikel hasil dari pembakaran daun kering yang secara unsur kimia sama dengan beberapa abu organik lainnya. Pustaka terkait menjelaskan bahwa menyatakan bahwa, "abu sekam padi banyak mengandung silika dan material pozzolan karena mengandung unsur kapur bebas yang dapat mengeras dengan sendirinya", [7]. Dengan demikian bahan berikut ini sangat efisien dalam bahan pendukung stabilisasi tanah ekspansif. Kombinasi Abu Daun yang akan digunakan bervariasi dengan jumlah jumlah 5\%, 10\%, 15\% dan 20\% dari berat total benda uji.

D. Semen portland

Dalam pengujian terdapat material pengikat yang digunakan adalah semen portland dengan dasar "sebagai media pengikat benda uji penelitian",[8], karena pada dasar unsur kimianya merupakan, "sebagai media pengikat meterial bangunan yang ekonomis dan ramah lingkungan",[9]. Semen portland sendiri adalah "bahan bangunan komposit yang terbuat dari kombinasi agregat dan pengikat semen",[10].

\subsection{Uji Konsistensi Tanah}

Pengujian konsistensi tanah dilakukan guna menentukan kadar air suatu tanah pada keadaan batas cair dan tingkat plastis maksimal. Pada pengujian konsistensi tanah terdapat 2 pokok pengujian, yaitu uji Liquid limit dan Plastic limit dengan metode pengujian adalah sebagai berikut : 


\section{[1] Liquid limit}

a. Letakkan 200 gram benda uji kering di atas mangkuk porselen, tambahkan air suling, lalu aduk dengan spatula sampai merata atau homogen.

b. Aturlah tinggi jatuh cawan $5 \mathrm{~mm}$ dengan memutar sekrup yang tercatat dibelakang alat liquit limit (cassagrande).

c. Atur penggunaan tanah dalam mangkuk porselen menjadi 4 bagian dan masukkan kedalam cawan monel cassagrande perbagian serta ratakan hingga sejajar dengan dasar alat liquit limit.

d. Tekan grooving tool pada benda uji yang telah diuji sepanjang diameternya dan grooving tool harus berkedudukan horizontal tegak lurus pada permukaan cawan cassagrande, sedangkan ujung grooving tersebut harus tidak lebih dari $1,5 \mathrm{~cm}$ tebalnya.

e. Putar handlenya 2 kali putaran perdetik sehingga kedua belahan benda yang diuji akan bersatu sepanjang $13 \mathrm{~mm}$.

f. Catat perhitungan sebagai number of blows (jumlah ketukan).

g. Jaga ke 4 pengujian untuk mendekati 25 ketukan, bila jumlah ketukan $<25$ maka benda uji kurang air atau jika $<25$ ketukan maka benda uji terlalu banyak air. jika hasilnya belum mendekati maka dapat diulangi lagi dengan penambahan air suling yang bervariasi sesuai dengan kondisi benda uji.

h. Ambil sebagian benda uji pada bagian yang menyatu, masukkan kedalam container untuk dikeringkan (oven) dan hitung kadar airnya.

\section{[2] Plastic Limit}

a. Gunakan tanah dengan lolos ayakan no. 40 (sebagian dari penelitian batas cair) sebanyak \pm 20 gram dan jumlah variasi formula mix tanah dengan limbah ampas kopi, diletakkan diatas mangkok porselen dan diaduk sampai merata kadar airnya.

b. Buatlah bola kelereng berdiameter $1 \mathrm{~cm}$.

c. Giling diatas pelat kaca dengan tangan. Penggilingan dengan telapak tangan dengan kecepatan $80-90$ gilingan permenit.

d. Penggilingan dilakukan terus sampai benda uji membentuk batang lidi dengan diameter 3 $\mathrm{mm}$. Bila pada waktu penggilingan ternyata sebelum benda uji mencapai diameter $3 \mathrm{~mm}$ sudah retak. Maka benda uji disatukan kembali, ditambahkan air sedikit dan diaduk sampai merata.

e. Sampel yang tepat bila pada diameter $3 \mathrm{~mm}$ telah menjukkan keadan retak-retak rambut. 
f. Ambil hingga 4 sampel pengujian dan masukkan dalam container dan tentukan kadar airnya.

\subsection{Uji Kepadatan Tanah (Proctor)}

Maksud dari uji proctor dapat dijelaskan dalam, "menaikkan kerapatan tanah dengan memperkecil jarak antar partikel sehingga terjadi reduksi volume udara dan tidak terjadi perubahan volume air yang cukup berarti”, [7]. Adapun langkah - langkah yang dilakukan pengujian proctor adalah sebagai berikut :

[1] Hitung nilai berat dan volume isi mold proctor menggunakan jangka sorong dan tentukan nilai volume berat isinya.

[2] Pasang alas dan leher mold proctor dan masukkan sedikit - demi sedikit benda uji kedalam mold proctor hinga menjadi 3 layer dengan setiap layer dilakukan penumbukan pada alat penumbuk sebanyak $25 \mathrm{x}$ tumbukan.

[4] Lepaskan alas dan leher mold proctor dan lakukan perataan permukaan benda uji menggunakan pisau pemotong.

[5] Hitung kembali berat mold proctor ketika terisi benda uji.

[6] Keluarkan benda uji dari mold proctor menggunakan dongkrak hidrolis dan tentukan kadar airnya menggunakan oven.

\section{HASIL DAN PEMBAHASAN}

\subsection{Uji Konsistensi Tanah}

Hasil pengujian Konsistensi tanah dapat disajikan dalam tabel dan grafik berikut ini :

TABEL 3.2 Nilai pengujian batas konsistensi tanah

\begin{tabular}{|c|c|c|c|}
\hline KADAR ABU DAUN (\%) & Nilai Luquid Limit (\%) & Nilai Plastic Limit (\%) & Index Plastic (\%) \\
\hline 0 & 46 & 19,37 & 26,63 \\
\hline 5 & 52 & 22,75 & 29,25 \\
\hline 10 & 56 & 24,49 & 31,51 \\
\hline 15 & 60 & 25,56 & 34,44 \\
\hline 20 & 62 & 30,25 & 31,75 \\
\hline
\end{tabular}

Sumber: Hasil Analisis Uji Konsistensi tanah di Laboratorium Teknik Sipil Universitas Kadiri 


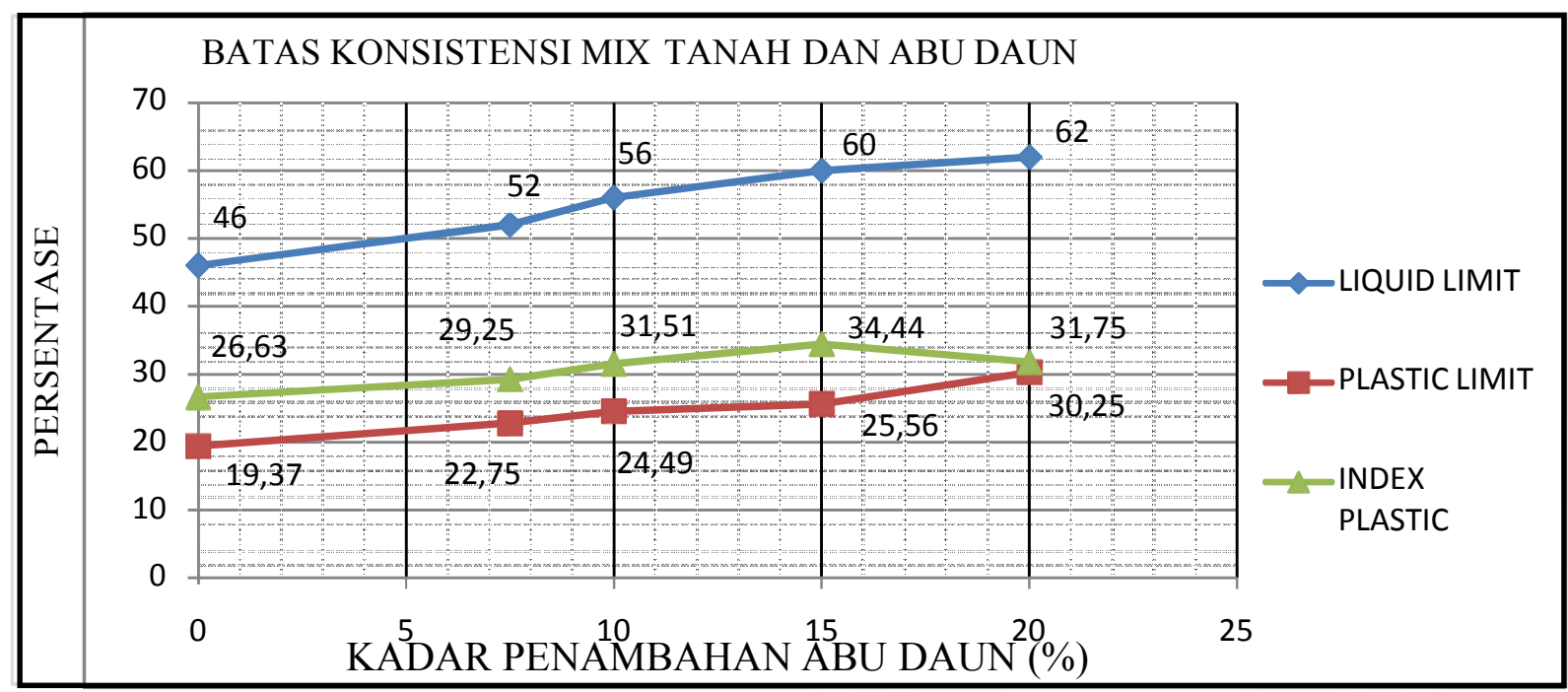

Sumber: $\quad$ Hasil Analisis Uji Batas Konsistensi Keseluruhan Benda Uji Mix Tanah dan Abu daun di Laboratorium Teknik Sipil Universitas Kadiri

Gambar 3.1. Grafik nilai batas konsistensi

Dari penelitian dan perhitungan uji konsistensi, Pada indeks plastisitas benda uji dengan penambahan $0 \%$ abu daun (Tanah Asli) memiliki persentase sejumlah 26,63\% dan pada perbaikan tanah dengan kombinasi abu daun, variasi penambahan sebesar $15 \%$ menunjukkan nilai index plastic struktur tanah konsisten optimal, yaitu sebesar 34,44\%.

\subsection{Uji Pemadatan Tanah}

Hasil pengujian pada pemadatan tanah (proctor) disajikan dalam tabel - tebel dan gambar grafik berikut ini :

TABEL3.3 NILAI UJI PROCTOR BENDA UJI STRUKTUR TANAH ASLI (Montmorillonite).

\begin{tabular}{|c|c|c|c|c|}
\hline BENDA UJI & 1 & 2 & 3 & 4 \\
\hline BERAT MOLD PROCTOR & 4502 & 4502 & 4502 & 4502 \\
\hline WEIGHT WATER $(\mathrm{Ww})+$ MOLD & 6242 & 6286 & 6493 & 6459 \\
\hline BERAT BENDA UJI (W) & 1740 & 1784 & 1991 & 1957 \\
\hline WEIGHT SOLID (Ws) & 1641 & 1651 & 1810 & 1747 \\
\hline WEIGHT WATER $(\mathrm{Ww})=\mathrm{W}-\mathrm{Ws}$ & 99 & 133 & 181 & 210 \\
\hline WATER CONTENT $(\mathrm{Wc})=\mathrm{Ww} / \mathrm{Ws}^{*} 100(\%)$ & 6,03 & 8,06 & 10,00 & 12,02 \\
\hline $\operatorname{VOLUME~MOLD~}(\mathrm{V})=\pi \cdot \mathrm{r}^{2} . \mathrm{t}$ & 188,28 & 188,28 & 188,28 & 188,28 \\
\hline WEIGHT VOLUME (ysat) = W/V & 9,24 & 9,48 & 10,57 & 10,39 \\
\hline WEIGHT VOLUME SOLID $(\mathrm{\gamma d})=\mathrm{Ws} / \mathrm{V}$ & 8,72 & 8,77 & 9,61 & 9,28 \\
\hline
\end{tabular}

Sumber : Data diolah

Pengujian proctor pada benda uji struktur tanah asli menunjukkan nilai optimum yd sebesar 9,61 pada kadar air sejumlah $10,57 \%$. 
TABEL 3.4UJI PROCTOR KOMBINASI TANAH DENGAN 5\% ABU DAUN.

\begin{tabular}{lccccc}
\hline BENDA UJI & 1 & 2 & 3 & & $\dot{4}$ \\
\cline { 2 - 6 } BERAT MOLD PROCTOR & 4502 & 4502 & 4502 & 4502 \\
WEIGHT WATER (Ww) + MOLD & 6319 & 6472 & 6665 & 6621 \\
BERAT BENDA UJI (W) & 1817 & 1970 & 2163 & 2119 \\
WEIGHT SOLID (Ws) & 1712 & 1823 & 1965 & 1891 \\
WEIGHT WATER $(\mathrm{Ww})=\mathrm{W}-\mathrm{Ws}$ & 105 & 147 & 198 & 228 \\
WATER CONTENT $(\mathrm{Wc})=\mathrm{Ww} / \mathrm{Ws} * 100(\%)$ & 6,13 & 8,06 & 10,08 & 12,06 \\
VOLUME MOLD $(\mathrm{V})=\pi \cdot \mathrm{r}^{2} . \mathrm{t}$ & 188,28 & 188,28 & 188,28 & 188,28 \\
WEIGHT VOLUME $(\mathrm{\gamma sat})=\mathrm{W} / \mathrm{V}$ & 9,65 & 10,46 & 11,49 & 11,25 \\
WEIGHT VOLUME SOLID $(\mathrm{\gamma d})=\mathrm{Ws} / \mathrm{V}$ & 9,09 & 9,68 & 10,44 & 10,04 \\
\hline
\end{tabular}

Sumber : Data diolah

Pengujian proctor pada benda uji kombinasi struktur tanah dengan 5\% ampas kopi menunjukkan nilai optimum yd sebesar 10,44 pada kadar air sejumlah 10,08\%.

TABEL3.5UJI PROCTOR KOMBINASI TANAH DENGAN 10\% ABU DAUN.

\begin{tabular}{lcccc}
\cline { 2 - 3 } BENDA UJI & 1 & 2 & 3 & 4 \\
\cline { 2 - 3 } BERAT MOLD PROCTOR & 4502 & 4502 & 4502 & 4502 \\
WEIGHT WATER $(\mathrm{Ww})+$ MOLD & 6342 & 6534 & 6775 & 6801 \\
BERAT BENDA UJI $(\mathrm{W})$ & 1840 & 2032 & 2273 & 2299 \\
WEIGHT SOLID $(\mathrm{Ws})$ & 1752 & 1881 & 2066 & 1999 \\
WEIGHT WATER $(\mathrm{Ww})=\mathrm{W}-\mathrm{Ws}$ & 88 & 151 & 207 & 300 \\
WATER CONTENT $(\mathrm{Wc})=\mathrm{Ww} / \mathrm{Ws} * 100(\%)$ & 5,02 & 8,03 & 10,02 & 15,01 \\
VOLUME MOLD $(\mathrm{V})=\pi \cdot \mathrm{r}^{2} . \mathrm{t}$ & 188,28 & 188,28 & 188,28 & 188,28 \\
WEIGHT VOLUME $(\mathrm{ysat})=\mathrm{W} / \mathrm{V}$ & 9,77 & 10,79 & 12,07 & 12,21 \\
WEIGHT VOLUME SOLID $(\mathrm{\gamma d})=\mathrm{Ws} / \mathrm{V}$ & 9,31 & 9,99 & 10,97 & 10,62
\end{tabular}

Sumber : Data diolah

Pengujian proctor pada benda uji kombinasi struktur tanah dengan $10 \%$ ampas kopi menunjukkan nilai optimum yd sebesar 10,97 pada kadar air sejumlah 10,02\%.

TABEL3.6UJI PROCTOR KOMBINASI TANAH DENGAN 15\% ABU DAUN.

\begin{tabular}{lccccc}
\hline BENDA UJI & \multicolumn{1}{c}{1} & 2 & 3 & 4 & \\
\cline { 2 - 6 } BERAT MOLD PROCTOR & 4502 & 4502 & 4502 & 4502 \\
WEIGHT WATER (Ww) + MOLD & 6432 & 6675 & 6895 & 6922 \\
BERAT BENDA UJI (W) & 1930 & 2173 & 2393 & 2420 \\
WEIGHT SOLID (Ws) & 1838 & 2012 & 2175 & 2104 \\
WEIGHT WATER $(\mathrm{Ww})=\mathrm{W}-\mathrm{Ws}$ & 92 & 161 & 218 & 316 \\
WATER CONTENT $(\mathrm{Wc})=\mathrm{Ww} / \mathrm{Ws} * 100(\%)$ & 5,01 & 8,00 & 10,02 & 15,02 \\
VOLUME MOLD $(\mathrm{V})=\pi . \mathrm{r}^{2} . \mathrm{t}$ & 188,28 & 188,28 & 188,28 & 188,28 \\
WEIGHT VOLUME $(\mathrm{ysat})=\mathrm{W} / \mathrm{V}$ & 10,25 & 11,54 & 12,71 & 12,85 \\
WEIGHT VOLUME SOLID $(\mathrm{\gamma d})=\mathrm{Ws} / \mathrm{V}$ & 9,76 & 10,69 & 11,55 & 11,17 \\
\hline
\end{tabular}

Sumber : Data diolah

Pengujian proctor pada benda uji kombinasi struktur tanah dengan 15\% ampas kopi menunjukkan nilai optimum yd sebesar 11,55 pada kadar air sejumlah 10,02\%. 
TABEL 3.7 UJI PROCTOR KOMBINASI TANAH DENGAN 20\% ABU DAUN.

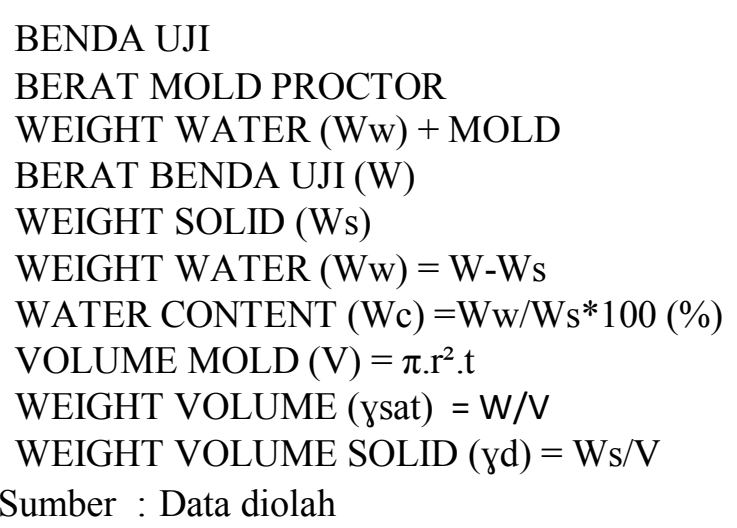

\begin{tabular}{cc}
\hline 1 & 2 \\
\hline 4502 & 4502 \\
6501 & 6710 \\
1999 & 2208 \\
1904 & 2044 \\
95 & 164 \\
4,99 & 8,02 \\
188,28 & 188,28 \\
10,62 & 11,73 \\
10,11 & 10,86 \\
\hline
\end{tabular}

\begin{tabular}{cc}
\cline { 2 - 2 } 3 & 4 \\
\cline { 2 - 2 } 4502 & 4502 \\
6940 & 6950 \\
2438 & 2448 \\
2216 & 2129 \\
222 & 319 \\
10,02 & 14,98 \\
188,28 & 188,28 \\
12,95 & 13,00 \\
11,77 & 11,31 \\
\hline
\end{tabular}

Pengujian proctor pada benda uji kombinasi struktur tanah dengan 20\% ampas kopi menunjukkan nilai optimum yd sebesar 11,77 pada kadar air sejumlah 10,02\%.

TABEL 3.8 Hasil Konversi Uji PROCTOR Dengan Berat Jenis

\begin{tabular}{|c|c|c|c|}
\hline AMPAS KOPI & NILAI PROCTOR $(\mathrm{\gamma d})$ & BERAT JENIS (Bj) & HASIL $(\mathrm{C}: \mathrm{Bj}) \mathrm{gr} / \mathrm{cm} 3$ \\
\hline 0 & 9,61 & 2,66 & 3,61 \\
\hline 5 & 10,44 & 2,55 & 4,09 \\
\hline 10 & 10,97 & 2,51 & 4,37 \\
\hline 15 & 11,55 & 2,44 & 4,73 \\
\hline 20 & 11,77 & 2,37 & 4,97 \\
\hline
\end{tabular}

Sumber : Data diolah

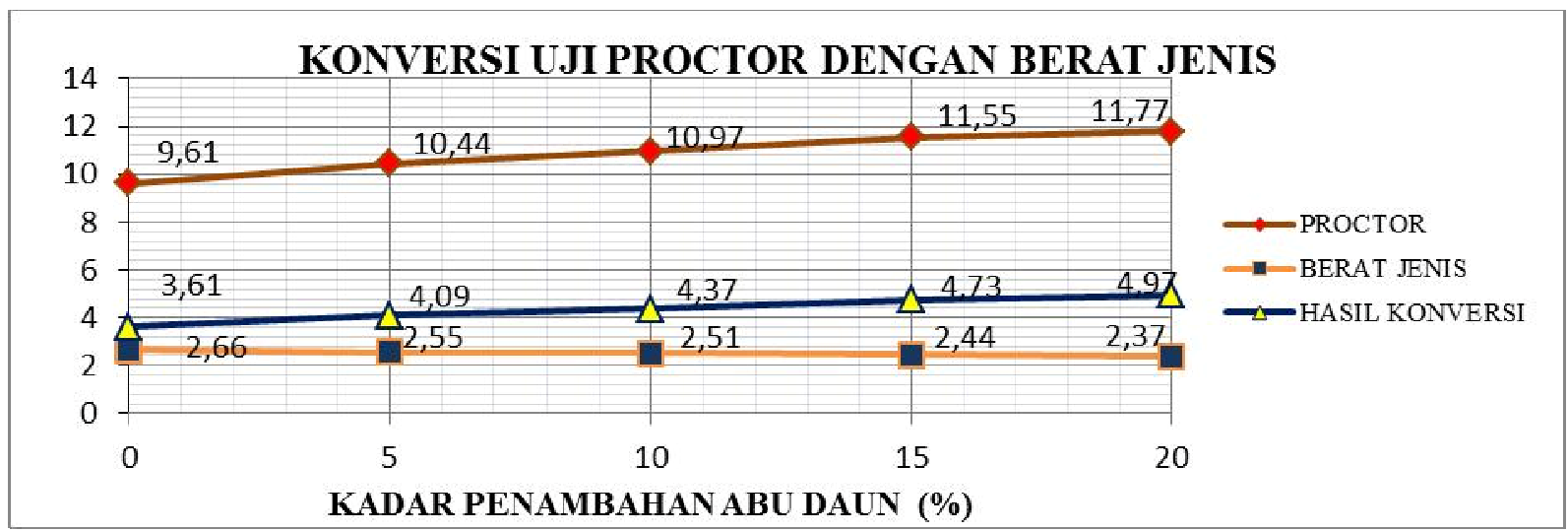

Sumber : Data konversi uji proctor dengan berat jenis

Gambar 3.1. Grafik perbandingan pengujian proctor pada benda uji

Nilai yang ditunjukkan pada perhitungan tersebut adalah ketika benda uji struktur tanah asli memiliki berat volume kering ( $\mathrm{yd}$ ) sebesar 3,61, pada kombinasi tanah asli dengan 5\% ampas kopi menunjukkan nilai berat volume kering ( $\mathrm{gd}$ ) sebesar $4,03 \mathrm{gr} / \mathrm{cm}^{3}, 10 \%$ sebesar $3,36 \mathrm{gr} / \mathrm{cm}^{3}, 15 \%$ sebesar $4,73 \mathrm{gr} / \mathrm{cm}^{3}$ dan pada penambahan sejumlah $20 \%$ adalah sebesar $4,97 \mathrm{gr} / \mathrm{cm}^{3}$. 


\section{PENUTUP}

\section{KESIMPULAN}

Pada perhitungan Index Plastic terbesar adalah pada benda uji tanah asli dengan penambahan Abu daun sejumlah 15\% yang memiliki tingkat selisih liquid limit dan plastic limit paling tinggi, yakni $34,44 \%$. Pada pengujian pemadatan tanah benda uji dengan penambahan abu daun sebesar $20 \%$ dari berat benda uji adalah hasil optimum uji pemadatan setelah dilakukan konversi keselarasan berat jenis. Yakni memiliki nilai berat volume kering ( $\mathrm{gd}$ ) sebesar 4,97 gr/cm3. Nilai tersebut merupakan nilai kepadatan diatas rata - rata pengujian jika dibanding dengan benda uji yang lainnya.

\section{SARAN}

Dengan acuan pada batasan masalah yang tidak memperhitungkan nilai ekonomis dalam pengaplikasian, sebagai praktisi maupun aplikator dalam pengerjaan suatu kegiatan stabilitas tanah menggunakan abu daun diharapkan selalu memperhitungkan segala resiko pembiayaan. 


\section{DAFTAR PUSTAKA}

[1] A. I. Candra, "STUDI KASUS STABILITAS STRUKTUR TANAH LEMPUNG PADA JALAN TOTOK KEROT KEDIRI MENGGUNAKAN LIMBAH KERTAS," UKaRsT, vol. 2, no. 2, p. 11, 2018.

[2] T. Pancang, "Perencanaan pondasi tiang pancang," pp. 1-9.

[3] A. Susanto, "PENGARUH STABILISASI TANAH LEMPUNG DENGAN ASPAL EMULSI Klasifikasi tanah,” vol. 3, no. KoNTekS 3, pp. 6-7, 2009.

[4] H. A 'la, B. Setiawan, and N. Djarwanti, "Penambahan Limbah Plastik Pada Tanah Ekspansif,"no. 36, pp. 1170-1178, 2017.

[5] Das Braja M, Mekanika Tanah (Prinsip-Prinsip Rekayasa Geoteknis) Jilid 1, vol. 1. Erlangga,1988.

[6] Y. C. S. Poernomo, Pengukuran kadar air tanah menggunakan gypsum block, vol. 2, no. 1.2008.

[7] M. R. Abdurrozak et al., "STABILISASI TANAH LEMPUNG DENGAN BAHAN TAMBAH ABU SEKAM,” vol. XXII, no. 2, pp. 416-424, 2017.

[8] A. D. Krisna, D. S. Winarto, S. T. Mt, A. Ridwan, and S. E. S. T. Mt, "Penelitian Uji Kuat Tekan Beton Dengan Memanfaatkan Limbah Ampas Tebu Dan Zat Additif Sikacim Bonding Adhesive," jurmateks, vol. 2, no. 1, pp. 1-11, 2019.

[9] S. Winarto, "PEMANFAATAN SERAT IJUK SEBAGAI MATERIAL KEMAMPUAN BETON MENAHAN BEBAN TEKAN Studi Kasus: Pembangunan Homestay Singonegaran Kediri,” vol. 1, no. 1, pp. 1-38, 2017.

[10] A. I. Candra and E. Siswanto, "REKAYASA JOB MIX BETON RINGAN MENGGUNAKAN HYDROTON DAN MASTER EASE 5010,”J. CIVILA, vol. 3, no. 2, p. 162, Oct. 2018.

[11] Wardani, S. P. R. (2008). Pemanfaatan limbah batubara (Fly Ash) untuk stabilisasi tanah maupun keperluan teknik sipil lainnya dalam mengurangi pencemaran lingkungan.

[12] Desiani, A. (2012). Stabilisasi Tanah Lempung Menggunakan Soil Binder. Jurnal Teknik Sipil, 8(1), 61-74.

[13] Andriani, A., Yuliet, R., \& Fernandez, F. L. (2012). Pengaruh Penggunaan Semen sebagai Bahan Stabilisasi pada Tanah Lempung Daerah Lambung Bukit terhadap Nilai Cbr Tanah. Jurnal Rekayasa Sipil (JRS-Unand), 8(1), 29-44.

[14] Mina, E., Kusuma, R. I., \& Ridwan, J. (2017). Stabilisasi tanah lempung menggunakan pasir laut dan pengaruhnya terhadap nilai kuat tekan bebas (Studi Kasus: Jalan Mangkualam Kecamatan Cimanggu-Banten). Jurnal Fondasi, 6(2).

[15] Gunasro, A., Nuprayogi, R., Partono, W., \& Pardoyo, B. (2017). Stabilisasi Tanah Lempung Ekspansif Dengan Campuran Larutan Naoh 7, 5\%. Jurnal Karya Teknik Sipil, 6(2), 238245. 